
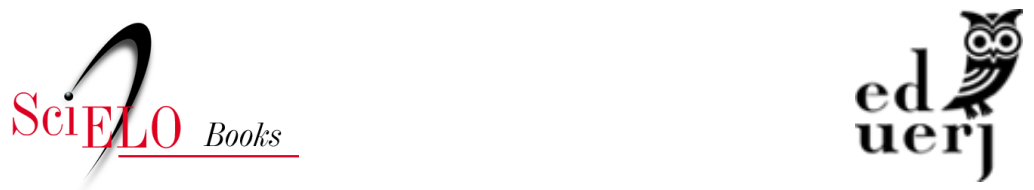

\title{
Capítulo 7. Autoscopia como recurso na formação de pais para intervenção com seus filhos com autismo
}

\author{
Carlo Schmidt \\ Jéssica Jaíne Marques de Oliveira
}

\section{SciELO Books / SciELO Livros / SciELO Libros}

SCHMIDT, C., and OLIVEIRA, J. J. M. O. Autoscopia como recurso na formação de pais para intervenção com seus filhos com autismo. In: NUNES, L. R. D. P., ed. Autoscopia: uma ação reflexiva sobre a prática docente [online]. Rio de Janeiro: EDUERJ, 2020, pp. 225-256. ISBN: 97865-87949-10-9. https://doi.org/10.7476/9786587949109.0009.

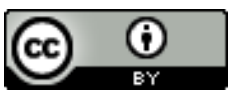

All the contents of this work, except where otherwise noted, is licensed under a Creative Commons Attribution 4.0 International license.

Todo o conteúdo deste trabalho, exceto quando houver ressalva, é publicado sob a licença Creative Commons Atribição 4.0.

Todo el contenido de esta obra, excepto donde se indique lo contrario, está bajo licencia de la licencia Creative Commons Reconocimento 4.0. 


\title{
Capítulo 7 \\ Autoscopia como recurso na formação de pais para intervenção com seus filhos com autismo
}

\author{
Carlo Schmidt \\ Jéssica Jaine Marques de Oliveira
}

\section{Introduçáo}

Sendo o autismo uma condição marcada por dificuldades de comunicação e sociais importantes, intervençôes que busquem minimizar o impacto sobre a vida dessas pessoas e suas famílias são essenciais. Atualmente, encontra-se disponível uma série de intervençôes específicas para pessoas com autismo - cujos resultados se mostram encorajadores -, conhecidas como Práticas Baseadas em Evidências (PBE). ${ }^{1}$ Derivadas das áreas da Saúde e da Educação, as $\mathrm{PBE}$ consistem em uma abordagem que prevê uma sequência de passos que as pesquisas devem seguir para que seus resultados possam ser comparados entre si e identificar evidências de efetividade (Reichow et al., 2008). Aquelas práticas que atendem a rigorosos critérios metodológicos e relatam resultados positivos sáo agrupadas e publicadas por agências internacionais como a National Profes-

1 Para mais detalhes, ver Debora Nunes e Carlo Schmidt. Educação especial e autismo: das práticas baseadas em evidências à escola. Disponível nas referências, ao final deste capítulo. 
sional Developmental Center (NPDC, 2019) e a National Research Council (NRC, 2001) como Práticas Baseadas em Evidências.

Entre as PBE reconhecidas por essas agências, especificamente uma delas tem recebido destaque recente: a Intervenção Implementada pelos Pais (IIP). Com onze estudos experimentais de caso único e nove estudos com grupos de crianças entre 2 e 11 anos de idade, a IIP tem atendido aos critérios exigidos pela NPDC para ser considerada uma PBE (Wong et al., 2014). Trata-se de uma forma de intervenção em que os profissionais orientam os pais a intervirem diretamente em determinadas habilidades de seu filho com autismo, como a comunicação social, a conversação, a linguagem espontânea e a atenção compartilhada (Wetherby et al., 2014).

A ideia de que os pais desempenham um papel crítico no desenvolvimento de habilidades sociocomunicativas dos filhos não é nova. Por exemplo, ao conversarem e sorrirem de forma sincrônica com os filhos, os pais apresentam a eles a natureza recíproca das interaçóes sociais. Quando aponta para um animal que se move e diz "cachorro", a criança aprende a associar essa palavra com o bicho correspondente e, assim, sucessivamente essas interaçóes constroem o desenvolvimento socioemocional e de linguagem do filho (Charlop et al., 2018). A teoria que subjaz a essa intervenção é de que mudanças nos comportamentos parentais tendem a provocar mudanças na criança (Kashinath et al., 2006).

$\mathrm{Na}$ IIP, os pais são encorajados a se engajarem intensamente na intervenção para que, além dos benefícios à criança, a intervenção também possa incrementar recursos do casal, como o empoderamento parental (Stahmer e Pellecchia, 2015). Isso porque um dos construtos teóricos que sustenta a IIP é a teoria dos sistemas familiares (Bowen, 1974). Para exemplificar a família como um sistema interconectado, podemos tomar como exemplo as interaçôes entre os pais e o filho com autismo. As crianças com TEA geralmente possuem dificuldades de iniciar e responder a interaçóes sociais. Como resultado, elas podem não responder às tentativas 
de interaçôes sociais dos pais. Quando as tentativas de interação social são frustradas, sem resposta, há uma tendência de que os pais diminuam suas tentativas para interagir com o filho, o que, por sua vez, tende a empobrecer ainda mais a qualidade das relaçóes familiares. Os pais sentem-se, então, estressados e desconectados de seus filhos, enquanto a criança vai se isolando das interaçóes e comunicaçóes (Zaidman-Zait et al., 2014).

Por outro lado, quando os pais se utilizam de estratégias efetivas para ganhar a atenção e interagir com o filho, este estará mais propenso a responder, e, assim, as tentativas de interação dos pais entram em sincronia com as respostas da criança, desenvolvendo relaçóes sociais positivas (Norton e Drew, 1994). Quanto mais iniciativas de sucesso tiverem os pais, mais oportunidades para o desenvolvimento social terá seu filho. Com isso, a resposta da família tende a ser a redução do estresse e maior confiança, uma vez que estarão de posse das habilidades para ajudar seu filho (Cidav et al., 2012).

Amsbary e Afirm Team (2017) apresentam um agrupamento das evidências que sustentam essa intervenção, incluindo um protocolo para sua implementação que orienta sobre os passos essenciais a serem seguidos. Dentre eles é destacada a importância de identificar pontos fortes e dificuldades da criança ao longo da rotina familiar, identificar os objetivos centrais a que se destina a intervenção (áreas-alvo) e as estratégias para alcançá-los. A partir de então, compartilha-se o plano de intervençáo com os pais, tornando-os cientes e participantes ativos desse processo.

Atenção especial é dada à formação dos pais. Nessa etapa, os pais e profissionais devem construir uma agenda conjunta sobre a intervenção, planejando claramente os objetivos e como prossegui-los. Charlop et al. (2018) enfatizam que o propósito dos encontros dos profissionais com os pais é observar a implementação e o desenvolvimento da intervençáo, assim como monitorar os progressos da criança. Para habilitar os pais a conduzirem a intervenção, um 
destaque deve ser dado à aprendizagem parental por meio da análise conjunta de sua performance, seguida de feedback, reflexáo conjunta e plano de ação.

É interessante observarmos que a metodologia descrita como forma de prática formativa, bem como o acompanhamento da implementação, mostra-se de modo muito similar ao processo de autoscopia. Ambas obedecem a uma observação e uma reflexão conjuntas entre profissionais e agentes de intervençáo para o desenvolvimento e o refinamento de habilidades. Contudo, também é consenso de que somente a observação de sua prática, isoladamente, pelo agente de intervenção não seria suficiente. Para que ocorra uma mudança de comportamento, é preciso que o agente de intervençáo desenvolva um conhecimento técnico prévio sobre a prática que está sendo implementada e também que receba orientaçâo direta de profissionais que complementem suas reflexóes. Por isso, a IIP prevê dois momentos distintos na formação dos agentes de intervenção, sendo o primeiro a capacitaçáo técnica (training) e o segundo, o acompanhamento e o monitoramento dos pais (coaching parents) (Charlop et al., 2018).

Embora ainda seja baixo o volume de pesquisas internacionais sobre a autoscopia com alunos com autismo, conforme relatado na revisão de literatura que compõe o capítulo 1 deste livro, já é possível identificar evidências de eficácia sobre o uso desse recurso para a formação de professores na realidade brasileira (Schmidt et al., 2019). A autoscopia mostrou-se um recurso útil na formaçáo de professores de sala regular e de sala de recursos multifuncionais que atendem alunos com TEA, com base no Desenho Universal de Aprendizagem (DUA), descrito na pesquisa do capítulo dois. Além disso, os capítulos três e quatro relatam sua utilização para que os docentes desenvolvam recursos de Comunicaçáo Alternativa, nos princípios do Currículo Funcional Natural. Na realidade nacional, os capítulos cinco e seis utilizam a autoscopia no contexto da implementação do Plano Educacional Individualizado (PEI) e 
para introdução de símbolos táteis de comunicação alternativa. Destaca-se que esses estudos foram realizados com professores de alunos com autismo como participantes.

Nesse sentido, pouco se sabe sobre a utilização da autoscopia na formação de pais para atuarem diretamente na intervenção com seus filhos com autismo. Uma revisão da literatura nacional revelou que, entre os anos 2005 e 2009, dos 1.096 artigos, apenas 5\% (39) envolviam a temática família e autismo (Fernandes, 2009). Desses 39, apenas cinco estudos envolviam intervenções que incluíam ativamente os pais como agentes de intervenção.

Portanto, o objetivo deste capítulo é descrever o processo de autoscopia sendo utilizado no contexto da formação de pais, a fim de que estes atuem como agentes de intervenção diretamente no desenvolvimento de habilidades sociocomunicativas do filho.

\section{Método}

Participaram da pesquisa uma família composta pelo pai, pela mãe e seu filho com autismo. ${ }^{2} \mathrm{O}$ pai tinha 36 anos no momento da intervenção e trabalhava em uma empresa de viação férrea em uma cidade do interior do Rio Grande do Sul. A mãe, cinco anos mais nova, possuía formação técnica na área da Saúde, mas não exercia nenhuma atividade laboral no momento. O filho com autismo tinha a idade de 15 meses e náo frequentava a escola comum ou passava por qualquer outra intervenção quando foi avaliado por suspeita de Transtorno do Espectro Autista (TEA). Os sinais que levaram os pais a consultar um neuropediatra foram a falta de aconchego no colo e alteraçóes no contato visual (pouco frequente). $\mathrm{O}$ neuropediatra da sua cidade confirmou o diagnóstico de Transtorno do Espectro Autista utilizando os critérios do DSM-5 (APA, 2013).

2 Utilizaremos o nome fictício Pedro para nos referirmos ao menino do estudo, visando a manter o sigilo de sua identidade. 
A intervenção foi conduzida por uma aluna de mestrado (agente de intervenção), com formação em Educação Especial e experiência em autismo, acompanhada por uma bolsista de iniciação científica (assistente de pesquisa). A agente de intervenção conduziu os encontros com os pais organizando as sessôes, enquanto a assistente de pesquisa registrou as falas e auxiliou com provimento de materiais e outros recursos (p. ex.: apresentação das filmagens).

Foi utilizado um delineamento quase experimental de caso único do tipo A-B, definido por uma fase de linha de base seguida por uma de intervenção (Nunes e Walter, 2014). Observou-se o efeito da IIP (variável independente) sobre as habilidades sociocomunicativas da mãe e seu filho com autismo (variável dependente), sendo a autoscopia utilizada como metodologia de formaçáo dos pais. $\mathrm{Na}$ fase de linha de base, também conhecida como pré-tratamento (fase A), os pais foram convidados a brincar com o filho livremente em sua residência, sem orientaçôes sobre como deveriam atuar. Já na fase de tratamento (fase B), foram iniciadas as orientaçôes aos pais por meio dos encontros de autoscopia.

Todas as sessóes de brincadeiras da mãe com o filho foram filmadas, constituindo-se um material para a análise das variáveis do estudo. Para tanto, foi combinado com os pais que houvesse uma padronização das cenas, sendo definido que a interação com a criança seria conduzida pela mãe e filmada pelo pai, no local eleito como o mais apropriado da casa (sala de brinquedos). A máe, em um primeiro momento, hesitou em ser a responsável por realizar as atividades com o filho, pois relatou ter dificuldades para tal tarefa. Porém, em conversa com os pais, a agente de intervençáo sugeriu que a mãe conduzisse a intervenção justamente para que pudesse se sentir mais confiante em relação às trocas com o filho, e ela, então, aceitou. Após a filmagem, os vídeos foram enviados imediatamente aos pesquisadores por meio de um grupo fechado do Facebook (plataforma escolhida pelos pais) para compor o material a ser analisado nos encontros de autoscopia. 
Cada episódio filmado teve a duração de cinco minutos, ocorrendo com frequência semanal durante três meses, somando dezesseis encontros. A fase de linha de base compreendeu os quatro primeiros episódios, e foi encerrada após verificação da estabilidade dos comportamentos sociocomunicativos da díade (variância < 50\%). Já a fase de intervenção totalizou doze episódios de interação mãe-criança, seguidos por encontros entre pesquisadora, assistente de pesquisa e os pais (autoscopia). Para a análise, foi desconsiderado o primeiro minuto de cada filmagem por questóes de ambientaçáo dos participantes (warming up), sendo selecionados para análise apenas os quatro minutos restantes (Silva e Santos Rhodes, 2014).

As quatro filmagens que compunham a linha de base também foram utilizadas para a familiarização das avaliadoras (agente de intervenção e assistente de pesquisa) com o instrumento utilizado para codificação dos comportamentos sociocomunicativos (Protocolo para Observação da Interação Pais-Criança). As discordâncias entre avaliadores foram discutidas, dirimidas, e os respectivos vídeos, reavaliados. Em seguida, o cálculo da taxa de confiabilidade entre os observadores (total de concordâncias/total de comportamentos x 100) resultou em um índice de concordância de $75 \%$, o que é considerado aceitável para estudos dessa natureza (Sampieri et al., 2013).

Para avaliar as variáveis dependentes (habilidades sociocomunicativas entre a mãe e o filho com autismo) nos vídeos, foi utilizada uma adaptação do Protocolo para Observação da Interação Pais-Criança, de Bosa e Souza (2007). Esse instrumento permitiu codificar duas classes de comportamentos sociocomunicativos durante os episódios de interação pais-criança: 1) comportamentos maternos (Compartilhamento de Tópicos); e 2) comportamentos da criança (Atenção Compartilhada). A categoria materna de Compartilhamento de Tópicos aborda a descrição operacional de comportamentos verbais, não verbais e gestos usados pela máe para compartilhar um tópico com o filho. Já a categoria Atenção Compartilhada descreve uma série de comportamentos em que a 
criança tem por objetivo iniciar uma atividade/brincadeira, compartilhar interesses e descobertas com os pais, ou responder aos seus estímulos.

A variável independente do estudo, que marca o início da fase de intervenção, constitui-se das orientaçóes aos pais por meio da metodologia de autoscopia. Os participantes responderam inicialmente a uma ficha de dados sociodemográficos e a um roteiro de entrevista sobre o conhecimento e as expectativas dos pais sobre habilidades de comunicação do filho. Esses instrumentos coletaram dados a respeito de informaçóes gerais que eles possuíam (ou não) sobre o Transtorno do Espectro Autista (sinais, sintomas, causas etc.), os locais e o contexto das interaçôes diárias mais frequentes dos pais com a criança, rotinas familiares, desenvolvimento retrospectivo e comportamentos atuais da criança e expectativas parentais sobre o desenvolvimento do filho, incluindo a percepção sobre suas habilidades e dificuldades. Essas informaçóes foram utilizadas para o planejamento inicial do enquadramento da intervenção, conforme as diretrizes para implementação da IIP (Amsbary e Afirm Team, 2017). Além disso, serviram também para compor uma grade de conteúdos que faria parte do programa de formaçáo aos pais, complementando a observação dos vídeos (autoscopia).

Os tópicos selecionados para essa formação dos pais foram escolhidos de forma mista: a priori e a posteriori. Aqueles temas definidos antes de iniciar a intervenção (a priori) foram identificados a partir de demandas observadas nos vídeos da linha de base (estruturação do ambiente, diversificação das estratégias maternas, atenção compartilhada). Já os conteúdos escolhidos a posteriori passaram a fazer parte do programa de formação a partir da identificação de demandas familiares consideradas pelos pesquisadores como importantes para a intervenção, que emergiram durante os encontros de autoscopia com os pais (medicação, transtorno de sono, comportamentos disruptivos). Desse modo, os encontros foram organizados em um cronograma composto por conteúdos 
de caráter técnico (textos e temas a discutir), complementados pela autoscopia propriamente dita, ou seja, a observação conjunta dos vídeos entre profissionais e pais.

Os dados sobre as frequências dos comportamentos sociocomunicativos da mãe e da criança ainda foram submetidos ao Tau-U, que é um método para avaliar o tamanho do efeito de uma intervenção. Trata-se de uma forma de mensuração para dados não paramétricos, aferindo a não sobreposição entre duas fases (linha de base e intervenção) (Parker et al., 2011).

Já os dados trabalhados nas sessóes de autoscopia foram coletados mediante um diário de campo, o qual era preenchido pela pesquisadora após cada encontro com os pais durante a fase de intervenção. $\mathrm{O}$ diário foi construído especificamente para este estudo, e constituiu-se em quatro eixos: 1) temas do encontro; 2) orientaçôes dadas aos pais; 3) dúvidas parentais; e 4) engajamento dos pais às orientaçôes. Os dados do diário foram analisados qualitativamente, de forma descritivo-explicativa. A pesquisa foi aprovada pelo Comitê de Ética local (Protocolo n. ${ }^{\circ}$ CAAE: 49198115.2.0000.5346).

\section{Resultados e discussáo}

Foram apresentados inicialmente os resultados dos efeitos da Intervenção Implementada pelos Pais (IIP) sobre as habilidades sociocomunicativas da mãe e do filho com autismo. Em seguida, foi descrito como ocorreu o processo de autoscopia com os pais ao longo dos encontros.

Quanto aos efeitos da intervençáo, a figura 1 apresenta as frequências dos comportamentos maternos (Compartilhamento de Tópicos) e da criança (Atenção Compartilhada) durante as fases de linha de base e intervençáo. 
Figura 1 - Frequência das habilidades sociocomunicativas da díade

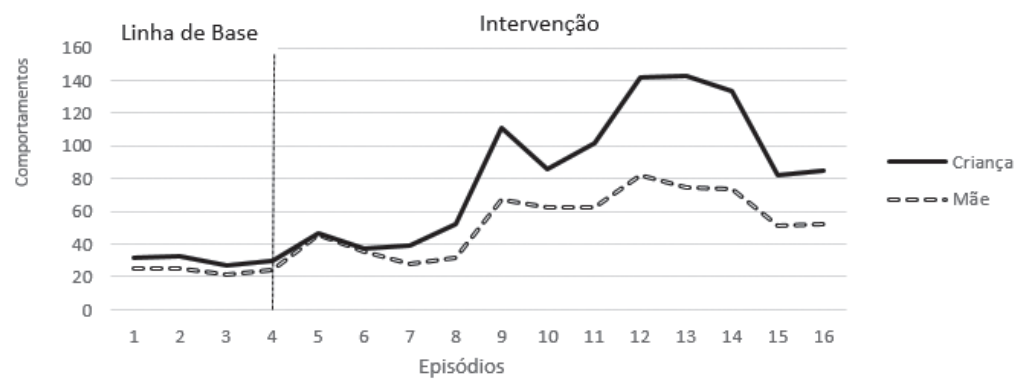

Fonte: Oliveira (2016).

Por inspeção visual, é possível observar uma estabilidade na fase de linha de base, seguida por uma tendência crescente na frequência de comportamentos sociocomunicativos da díade a partir da fase de intervenção. A porcentagem de mudanças dos comportamentos de atençáo compartilhada da criança foi de $66 \%$, o que pode ser considerada como limítrofe, mas ainda significativa, de acordo com os resultados do tratamento estatístico (Tau-U = $0,66 / p=0,05223)$. Já o tamanho do efeito da intervençáo para os comportamentos maternos de compartilhamento de tópico indicou $100 \%$ de mudança na fase de intervenção, em comparaçáo à linha de base. Apesar de não podermos confirmar a validade estatística do experimento, pois o valor de $p$ foi maior que 0,5 , é importante considerarmos a validade clínica, evidenciada pela curva ascendente na fase de intervenção (Tau- $\mathrm{U}=1,00 / p=0,0036)$. Esses dados confirmam que a autoscopia exerceu efeitos importantes sobre as frequências dos comportamentos maternos e da criança.

Quanto aos encontros de autoscopia, estes iniciaram após a finalização da fase de linha de base, quando os pais ainda não recebiam as orientaçóes por parte da educadora, e ocorreram na sala da residência da família, em um ambiente silencioso, que dispunha 
de um televisor para visualização das filmagens das intervençóes, durante aproximadamente uma hora e meia. As reunióes obedeciam a uma estrutura predefinida, que iniciava com os relatos da rotina familiar daquela semana, uma discussão sobre temas dos textos previamente combinados para aquele encontro, seguidas pela observação e discussão sobre as estratégias e os comportamentos maternos presentes nos vídeos.

O quadro 1 apresenta uma síntese dos materiais e temas trabalhados com os pais nos encontros e a descrição detalhada dos encontros de autoscopia.

Quadro 1 - Temas e materiais utilizados nos encontros com os pais

\begin{tabular}{|c|c|c|}
\hline Encontro & Temas e materiais & Autoscopia \\
\hline $1 .^{\circ}$ & $\begin{array}{l}\text { Breve histórico, conceituação e } \\
\text { critérios diagnósticos do Autismo: } \\
\text { áreas social e comportamentos. } \\
\text { Texto: Diretrizes de atençâo para } \\
\text { reabilitação de pessoas com TEA } \\
\text { (Brasil, 2014). }\end{array}$ & $\begin{array}{l}\text { Observaçóes: excesso de brin- } \\
\text { quedos e materiais de interesse } \\
\text { disponíveis simultaneamente ao } \\
\text { filho durante a intervenção. } \\
\text { Orientaçóes: reduzir a presença de } \\
\text { estímulos visuais do espaço. }\end{array}$ \\
\hline $2 . .^{\circ}$ & $\begin{array}{l}\text { Problemas de comportamentos no } \\
\text { autismo (sono, autoagressáo). } \\
\text { Texto: Problemas de comportamen- } \\
\text { to: conceituação e possibilidades de } \\
\text { intervençâo para pais e professores } \\
\text { (Silva e Cia, 2012). }\end{array}$ & $\begin{array}{l}\text { Observaçóes: foi observada sono- } \\
\text { lência e agitação do filho devido ao } \\
\text { distúrbio do sono e dificuldades no } \\
\text { compartilhamento da atenção para } \\
\text { objetos com a mãe. } \\
\text { Orientaçôes: manejo para hora } \\
\text { de dormir e desenvolvimento de } \\
\text { estratégias para uso do apontar, } \\
\text { indicando localizaçáo dos objetos. } \\
\end{array}$ \\
\hline $3 .^{\circ}$ & $\begin{array}{l}\text { Alterações sensoriais e Autismo } \\
\text { (Hipersensibilidade para sons e } \\
\text { tato). } \\
\text { Dúvidas parentais: dietas SGSC. } \\
\text { Objetividade na linguagem para a } \\
\text { pessoa com TEA. } \\
\text { Discussão sobre a atençáo compar- } \\
\text { tilhada no desenvolvimento. } \\
\text { Solicitação de registros, um diário. }\end{array}$ & $\begin{array}{l}\text { Observações: a criança começou } \\
\text { a utilizar o apontar com maior } \\
\text { frequência, porém ainda olhando } \\
\text { pouco para a máe. } \\
\text { Orientaçóes: orientaçóes sobre } \\
\text { como estimular o contato visual } \\
\text { nas interaçóes; demonstração de } \\
\text { atividades práticas utilizando o } \\
\text { olhar e o apontar com escolha } \\
\text { entre duas opçóes. }\end{array}$ \\
\hline
\end{tabular}




\begin{tabular}{|c|c|c|}
\hline $4 .^{\circ}$ & $\begin{array}{l}\text { Orientação visual entre mãe-crian- } \\
\text { ça: sincronia entre olhares. } \\
\text { Texto: Inclusão: um guia para edu- } \\
\text { cadores. Uma abordagem funcional } \\
\text { para lidar com o comportamento } \\
\text { desafiador grave (Stainback e Stain- } \\
\text { back, 1999). }\end{array}$ & $\begin{array}{l}\text { Observaçóes: a mãe sente-se mais } \\
\text { confiante para brincar com o filho; } \\
\text { identificação do cantar como ele- } \\
\text { mento para o engajamento. } \\
\text { Orientaçóes: Sugestáo de ativi- } \\
\text { dade para aumento do tempo de } \\
\text { engajamento; pais podem utilizar } \\
\text { mais da ludicidade para promover } \\
\text { brincadeiras, as quais influenciam } \\
\text { na atenção compartilhada. }\end{array}$ \\
\hline $5 .^{\circ}$ & $\begin{array}{l}\text { Engajamento na interação. } \\
\text { Quebra e mudanças nas rotinas. }\end{array}$ & $\begin{array}{l}\text { Observação: dupla está se engajan- } \\
\text { do mais nas atividades. } \\
\text { Orientaçóes: mostrar as peças } \\
\text { próximo ao rosto para aumentar } \\
\text { contato visual; orientação sobre } \\
\text { organização de ensino estrutura- } \\
\text { do (salientar estímulos centrais e } \\
\text { minimizar periféricos); importân- } \\
\text { cia da antecipaçáo das açóes para } \\
\text { compreensáo das intençóes. }\end{array}$ \\
\hline $6 .{ }^{\circ}$ & $\begin{array}{l}\text { Brincadeira simbólica: o que é } \\
\text { importante para seu desenvolvi- } \\
\text { mento? } \\
\text { Texto: Importância do brincar no } \\
\text { desenvolvimento da criança com } \\
\text { TEA (Bernert, 2013). }\end{array}$ & $\begin{array}{l}\text { Observaçóes: aumento de contato } \\
\text { visual da criança para rosto da } \\
\text { máe; importância de mudar de } \\
\text { foco quando um objeto distrai o } \\
\text { interesse para a interação. } \\
\text { Orientaçôes: exemplos de como os } \\
\text { pais podem mostrar e apontar para } \\
\text { os objetos da atividade ou brinca- } \\
\text { deira que estiverem executando. }\end{array}$ \\
\hline $7 .^{\circ}$ & $\begin{array}{l}\text { Comportamento esquivo de Pedro } \\
\text { com familiares; orientaçáo para } \\
\text { fazerem um álbum ou mostrarem } \\
\text { fotos dos parentes mais distantes } \\
\text { para que ele comece a reconhecer } \\
\text { quando eles os visitam. }\end{array}$ & $\begin{array}{l}\text { Observaçáo: a criança tem } \\
\text { mostrado mais calma com algo } \\
\text { que conhece o início, meio e fim; } \\
\text { discussáo sobre a imprevisibilidade } \\
\text { das açóes (antecipação). } \\
\text { Orientaçóes: mudança de foco } \\
\text { quando há irritação com a ativi- } \\
\text { dade, criatividade da máe (trocou } \\
\text { brincadeira planejada por outra de } \\
\text { encaixe). }\end{array}$ \\
\hline
\end{tabular}




\begin{tabular}{|c|c|c|}
\hline $8 .^{\circ}$ & $\begin{array}{l}\text { Apontar (protodeclarativo vs } \\
\text { protoimperativo). } \\
\text { Discussão sobre tempo excessivo } \\
\text { sozinho em frente à televisão. } \\
\text { Comunicação Alternativa: o que é? } \\
\text { (exemplos). }\end{array}$ & $\begin{array}{l}\text { Observações: melhora na mo- } \\
\text { tricidade ampla; maior tempo e } \\
\text { qualidade no engajamento da mãe } \\
\text { e do filho, maior expressão dos } \\
\text { sentimentos nas atividades. } \\
\text { Retomada da discussáo sobre } \\
\text { brincadeiras lúdicas para desenvol- } \\
\text { vimento da linguagem. } \\
\text { Orientaçóes: ideias para uma me- } \\
\text { lhor organizaçáo da rotina (buscou, } \\
\text { imprimiu e plastificou imagens } \\
\text { para organizar o banho). }\end{array}$ \\
\hline 9.0 & $\begin{array}{l}\text { Repertório restrito de atividades. } \\
\text { Mudança de horários do sono. } \\
\text { Observaçáo sobre aumento do } \\
\text { interesse restrito do filho por } \\
\text { algumas atividades (olhar TV), } \\
\text { discutimos formas de trazer novas } \\
\text { experiências e estímulos para ele. }\end{array}$ & $\begin{array}{l}\text { Observações: observação de bal- } \\
\text { bucios frequentes (como estimular } \\
\text { a fala). } \\
\text { Orientações: mãe avaliou negativa- } \\
\text { mente seu desempenho no vídeo, } \\
\text { porém a pesquisadora destacou as- } \\
\text { pectos positivos, o que fez com que } \\
\text { ela concordasse que está sabendo } \\
\text { brincar melhor. }\end{array}$ \\
\hline $10 .^{\circ}$ & $\begin{array}{l}\text { Atividades para estimular o desen- } \\
\text { volvimento motor. } \\
\text { Uso do Prompt (exemplos de } \\
\text { prompt físico, verbal e gestual). }\end{array}$ & $\begin{array}{l}\text { Observaçóes: a mãe e a criança } \\
\text { tiveram períodos mais extensos } \\
\text { de atenção compartilhada, com } \\
\text { atenção e contato visual, entendi- } \\
\text { dos como resultante da brincadeira } \\
\text { materna mais lúdica (atividades } \\
\text { com instrumentos musicais atraem } \\
\text { muito o interesse dele). } \\
\text { Orientaçóes: ideias maternas sobre } \\
\text { atividades com "circuito"; retoma- } \\
\text { da da confiança materna. }\end{array}$ \\
\hline
\end{tabular}




\begin{tabular}{|c|c|c|}
\hline $11 .^{\circ}$ & $\begin{array}{l}\text { Melhor interação, reflexo do me- } \\
\text { lhor engajamento dos pais. } \\
\text { Teoria da mente - conseguindo } \\
\text { fazer inferências sobre o desenvol- } \\
\text { vimento do filho. }\end{array}$ & $\begin{array}{l}\text { Observaçóes: proposta de atividade } \\
\text { motora; retomada da teoria da } \\
\text { mente no autismo. } \\
\text { Orientaçôes: brincadeira com tinta; } \\
\text { mãe utilizou a massinha de mo- } \\
\text { delar no rosto para maior contato } \\
\text { visual e teve êxito; muita atenção } \\
\text { compartilhada entre a díade; mãe } \\
\text { relatou sobre como se sente mais } \\
\text { feliz em ver seu próprio desempe- } \\
\text { nho por meio dos vídeos e também } \\
\text { em saber melhor lidar com seu } \\
\text { filho e as situaçóes. }\end{array}$ \\
\hline $12 .^{\circ}$ & $\begin{array}{l}\text { Autonomia na alimentação; apren- } \\
\text { dizagem por observaçáo (modela- } \\
\text { gem vicária). }\end{array}$ & $\begin{array}{l}\text { A importância de motivá-lo na } \\
\text { alimentação, já que conseguiu } \\
\text { sozinho e, quando necessário, dar o } \\
\text { apoio físico. } \\
\text { Orientaçôes: interação no momen- } \\
\text { to da alimentação; fechamento dos } \\
\text { encontros. }\end{array}$ \\
\hline
\end{tabular}

Fonte: Oliveira (2016).

Um dos aspectos observados durante a linha de base e nas tratativas iniciais sobre a intervenção foi a falta de informação dos pais sobre o autismo. Essa demanda torna-se relevante no sentido de que o entendimento teórico norteia as ações interventivas e, por isso, foi selecionado para o primeiro encontro um texto que abordasse as principais características do transtorno. A escolha foi por uma cartilha didática distribuída gratuitamente pelo Ministério da Saúde, em razão desse material se destinar a oferecer orientaçóes sobre o autismo não somente a equipes multidisciplinares, mas também especialmente aos familiares, visando ao cuidado à pessoa com TEA (Brasil, 2014). O material selecionado traz uma tabela contendo os indicadores precoces e sinais de alerta para TEA, descrevendo comportamentos comumente presentes em crianças com autismo de forma descritiva, sendo apresentados quatro principais pontos: comunicação, interação social, brincadeiras e alimentação. 
Como a família havia recebido o diagnóstico muito recentemente, os sinais identificados pelo neuropediatra náo estavam claros para eles, sendo importante discutir quais sinais de alerta eles identificavam no filho e como alguns comportamentos descritos pelos pais se relacionavam ou náo ao TEA. Nesse sentido, os pais não somente identificaram comportamentos que fugiam ao esperado para o desenvolvimento infantil (alteraçóes na orientação social, olhar e comportamentos interativos pouco frequentes, como o apontar), como também perceberam aspectos e habilidades preservados no filho que não diziam respeito ao autismo (vínculo afetivo com cuidadores, marcos do desenvolvimento motor).

Em seguida, os vídeos foram apresentados aos pais pela agente de pesquisa e sua assistente para observação e discussão. Os relatos maternos se mostraram recheados de sentimentos de insegurança ("eu acho que não consigo brincar com ele direito"), solicitando auxílio às profissionais. A observação conjunta direcionou a atenção para o ambiente onde a máe brincava com o filho, em que havia uma diversidade de brinquedos atrativos empilhados sobre a mesa, proporcionando um excesso de estímulos simultâneos à criança. Com isso, o foco de atenção era difuso, variando rapidamente de um brinquedo para o outro, resultando em uma exploração superficial e rápida que não permitia o aprofundamento das experiências de compartilhamento de tópicos. Em virtude disso, uma das orientaçóes da educadora foi de "limpar" o ambiente dos estímulos excessivos, disponibilizando apenas poucos brinquedos na mesa e explicando a ela a razão desse arranjo ambiental.

Destaca-se que o objetivo da intervenção era voltado ao desenvolvimento de habilidades sociocomunicativas da mãe e da criança, em que os comportamentos de atenção compartilhada se constituem basais. E, para que ocorram, é necessário que haja o compartilhamento de um tópico comum à díade, podendo ser este um dos brinquedos da sala. Com menos brinquedos, espera-se, como tendência, maior exploração de cada um. 
O segundo encontro teve início com os relatos semanais das rotinas familiares com o filho. As preocupaçôes parentais não diziam respeito às dificuldades sociais de Pedro, mas centravam-se em problemas comportamentais, tais como o sono e a autoagressividade. Relataram que o filho vem apresentando dificuldades em conciliar o sono, e que, mesmo indo se deitar próximo às 22 horas, apenas conseguia dormir no final da madrugada, quando o dia amanhece. Com isso, tanto Pedro quanto seus pais vinham dormindo pouco e apresentando sinais de estresse continuado, impactando sobre a qualidade de vida de ambos e, consequentemente, a intervenção.

A abordagem da pesquisadora sobre esse tema foi investigar as possíveis causas do transtorno do sono para a proposição de uma intervenção. A literatura científica mostra que esse problema é comum no autismo, pois dados apontam que entre 44\% e 86\% dessas crianças apresentam transtornos do sono, comparados com a taxa entre 10\% e 16\% para crianças sem autismo (Maxwell-Horn e Malow, 2017). Há indícios de pessoas no espectro do autismo que têm mais chances de apresentar mutaçóes genéticas que afetam os padróes de sono, modificando a qualidade da melatonina produzida e, assim, a alteração do sono (Yang et al., 2016). ${ }^{3}$ Portanto, foi indicado aos pais que levassem esse relato ao médico que acompanhava o filho para que o avaliasse. Mas, além das questões médicas, o manejo parental para regulação do ritmo circadiano foi abordado. Recomendou-se a criação de uma rotina para a hora de dormir em que obedecesse a um "ritual", iniciando pela hora do banho, seguido pela leitura de um livro infantil na cama até a hora de apagar a luz. A manutenção dessa sequência tende a exercer efeitos sobre o comportamento, preparando o corpo para o relaxamento e induzindo o sono.

3 A melatonina é um hormônio natural produzido pela glândula pineal, que é ativada pela pouca luz, à noite (Souders et al., 2017). 
Quanto ao comportamento de automutilação, os pais observaram que Pedro mordia o lado externo da mão em situaçóes de estresse, o que começava a causar uma lesão na pele. Pelos relatos do contexto em que esse comportamento ocorria, levantou-se a hipótese de estar acontecendo em razão da atenção que os pais demonstravam quando o filho se comportava dessa maneira, quando cessavam quaisquer atividades para tirar a máo da boca de Pedro. Assim, foi sugerida uma diminuição da atenção sobre as mordidas e que, em vez disso, chamassem a atenção do filho para outros brinquedos ou atividades do seu interesse, desviando assim o foco. Seguimos acompanhando o desenlace desses relatos nos encontros seguintes.

Após os relatos das rotinas familiares, prosseguiu-se com a observação dos vídeos da intervenção. Um dos temas discutidos foi sobre o comportamento sonolento de Pedro, que se mostrou hipoativo, com pouca iniciativa por ter dormido pouco na noite anterior. A baixa frequência de respostas interativas do filho fez com que a mãe avaliasse a intervenção como "ruim", atribuindo a si as dificuldades em manter a atenção de Pedro: "Acho que náo estou sabendo brincar direito com o Pedro." As orientaçóes à mãe nesse momento foram de que seu comportamento parecia adequado e contingente ao de Pedro, e que as dificuldades poderiam ser mais bem explicadas pelo sono do filho. Seguiu-se com algumas orientaçôes sobre a importância de estimular o uso do comportamento de apontar do filho, sendo sugerido que objetos de interesse fossem colocados a certa distância para que Pedro tivesse que apontar para eles quando necessário em vez de pegá-los com as mãos. Os pais mostraram-se atentos às discussóes e relataram que seguiriam essas indicaçóes, o que resultou em efeito positivo nos próximos encontros, nos quais os relatados concentraram-se mais no ato de automutilação.

No terceiro encontro, os relatos da rotina incluíram dificuldades em lidar com a alimentaçáo do filho, e que pensavam em iniciar uma dieta especial que viram em uma reportagem sobre 
autismo, pobre em glúten e caseína. Também trouxeram exemplos de comportamentos associados às alteraçôes sensoriais de Pedro, mais especificamente quando colocava as mãos sobre os ouvidos na presença de sons altos ou manipulava excessivamente objetos com as mãos. A pesquisadora combinou de enviar, por e-mail, alguns textos educativos e científicos sobre esse assunto aos pais, para que pudéssemos ocupar o tempo dos encontros com foco nos aspectos diretamente ligados à intervenção. Para isso, foi indicado que os pais anotassem suas questóes em um diário (agenda), evitando se esquecerem de relatar fatos importantes. Estes também poderiam ser enviados por e-mail para os pesquisadores.

$\mathrm{Na}$ observação subsequente aos vídeos, a mãe informou que sentia que o filho não a compreendia: "Eu acho que ele não está me entendendo bem, olha lá. Eu falo e explico de novo pra ele, mas ele não me atende". De fato, nas cenas da intervenção era possível observarmos que a linguagem utilizada pela máe era marcada por frases muito extensas, cujo conteúdo era inespecífico (p. ex.: "vamos brincar só mais um pouco", “o que você quer?”). As orientaçôes da pesquisadora foram a respeito das características da compreensão verbal de crianças com autismo. Foram expostas, por exemplo, algumas pesquisas que analisaram o desempenho de crianças com autismo em atividades ou jogos em que elas recebiam instruçôes verbais, comparadas com outras em que a criança era orientada sem essas instruçóes verbais (p. ex.: montar um quebra-cabeça). Os resultados mostram que há uma tendência a um melhor desempenho não verbal do que verbal (Mayes e Calhoun, 2003). A partir disso, foi discutida a dificuldade de compreensão verbal das crianças com autismo, e especificamente de Pedro, destacando a necessidade de que a mãe utilizasse uma comunicação verbal mais breve e objetiva, que facilitasse o entendimento das suas intençôes para com ele.

$\mathrm{O}$ quarto encontro iniciou com a discussão sobre a leitura prévia de um texto sobre estratégias para lidar com problemas de comportamento, o qual foi trazido em razão dos relatos sobre com- 
portamentos de autoagressão e desafiadores de Pedro. As situaçóes apresentadas como exemplos no livro foram comparadas com os comportamentos do filho, permitindo que as estratégias e termos técnicos fossem esclarecidos (p. ex.: uso de reforço diferencial para diminuir a frequência das mordidas de Pedro às suas mãos).

No momento da autoscopia, a mãe disse sentir-se mais confiante para se engajar em atividades interativas com o filho: "Essa hora eu já sabia que para manter a atenção dele eu precisava apresentar algo que ele gostasse, por isso escolhi começar a cantar. E funcionou! Fiquei muito feliz em ver que eu consigo!” A mãe se referia ao momento em que Pedro mostrava-se refratário às suas propostas de interação, e que ela começou a cantar uma das cançóes que o filho canta frequentemente. A resposta foi o direcionamento da atenção do filho para a mãe, cantando junto e se aproximando dela. Nesse momento, foi discutida a importância da troca sincronizada de olhares e verbalizaçóes como comportamentos centrais da atenção compartilhada, assim como o papel do compartilhamento da atenção para o desenvolvimento das intençóes comunicativas, cognição social e linguagem. Observou-se claramente a compreensão de ambos os pais sobre seu papel como agentes de intervenção e como eles poderiam auxiliar no desenvolvimento da comunicação do filho, entendendo que a ludicidade da interação proporciona mais engajamento social, e este é a base para outras habilidades.

No encontro seguinte, os pais iniciaram descrevendo cenas em que a rotina com Pedro foi quebrada, gerando agitaçáo e desorganização. Foi discutida a inflexibilidade cognitiva e comportamental no autismo, destacando como uma rotina estruturada poderia auxiliar o filho a compreender o que esperar e, assim, agir positivamente sobre os problemas de comportamento.

$\mathrm{Na}$ sessão de autoscopia, a mãe se mostrou orgulhosa de sua habilidade para brincar com o filho: "Olha lá, já tô conseguindo interagir com ele nas brincadeiras!” (sorrindo). Uma das observações foi sobre o olhar de Pedro estar direcionado apenas aos brinque- 
dos, sem a alternância entre a mãe e estes. Discutiu-se brevemente sobre os comportamentos que compóem a atençáo compartilhada e a importância do direcionamento da atençáo do parceiro aos objetos, em que o monitoramento do olhar do outro é essencial (Deak e Triesch, 2006). Com isso, foi identificada a necessidade de criação de uma estratégia materna para direcionar o olhar do filho para o seu rosto. Por iniciativa da própria mãe, sugeriu-se que os brinquedos de interesse de Pedro fossem apresentados a ele na linha do olhar, fazendo com que ocorresse o contato visual direto. Esse foi o primeiro momento em que a mãe não apenas se mostrou mais confiante em suas habilidades interativas, mas também propôs estratégias práticas para engajamento na interação a partir de uma compreensão dos objetivos da intervenção: o desenvolvimento de habilidades sociocomunicativas.

O sexto encontro com os pais abordou como tema previamente definido um texto sobre o brincar no contexto do desenvolvimento das habilidades sociocomunicativas do autismo. Foi a oportunidade de aprofundar as discussôes sobre construtos do desenvolvimento social infantil (p. ex.: cognição social, reconhecimento do outro como agente intencional, teoria da mente, entre outros) e como a brincadeira pode ser utilizada como intervençáo. $\mathrm{O}$ enfoque foi dado ao desenvolvimento cognitivo a partir da brincadeira na perspectiva histórico-cultural, em que as trocas interativas permitem o acesso a formas mais complexas de pensamento abstrato e funçôes psicológicas superiores (Morato, 1996).

$\mathrm{Na}$ sessão de autoscopia observou-se um aumento sensível do contato visual de Pedro com sua máe, muito possivelmente resultante das discussóes prévias sobre a importância do olhar e de estratégias práticas nesse sentido. Chamou a atenção da pesquisadora a análise dos pais sobre sua intervenção quando demonstraram compreensão a respeito do desenvolvimento infantil e do autismo, utilizando termos técnicos: "Pedro está direcionando o olhar mais 
pra mim, né? Espero que essa nossa atenção compartilhada ajude o desenvolvimento da linguagem e interação."

A brincadeira sugerida pela pesquisadora para estimular o contato visual dizia respeito ao esconder e aparecer (peekaboo). A mãe foi instruída a usar um pequeno lenço para esconder o rosto de Pedro, enquanto perguntava: "onde está a mamãe?". Logo em seguida, retira o lenço, mostrando o rosto e dizendo: "Tá aqui!". Essa brincadeira é muito utilizada em diferentes culturas com crianças bem pequenas para avaliação da permanência do objeto, durante o estágio sensório-motor proposto por Piaget (2003), porém, no contexto dessa intervenção, foi utilizada como elemento lúdico, cujo foco estava centrado na regiáo dos olhos. No vídeo, a mãe iniciou essa brincadeira para atrair a atenção de Pedro, que riu e sustentou sua atenção, engajando ambos em trocas afetivas síncronas de olhares. Em razão do resultado exitoso, a mãe utilizou a brincadeira de esconder e aparecer, com mais frequência, nas intervençôes subsequentes.

No sétimo encontro, o pai trouxe algumas dúvidas sobre eventos que ocorreram nas rotinas familiares, como uma visita de parentes em que Pedro se comportou de modo esquivo, evitando o contato e preferindo atividades solitárias. A família relatou que os parentes, em virtude das dificuldades comportamentais do filho, têm frequentado pouco sua casa, desejando mais aproximação entre eles. De fato, o afastamento entre família extensiva e família nuclear, em razão das dificuldades comportamentais no autismo, tem sido relatado na literatura (Abreu, 2012; Fávero e Santos, 2005). Para isso, a pesquisadora sugeriu a organização de um "álbum de família", com fotos dos parentes, para olhar com o filho, relacionando os nomes às fotos, ideia que foi bem acolhida pela mãe.

$\mathrm{Na}$ sessão de autoscopia, foi observado que a mãe repetiu a brincadeira de esconder e aparecer, resultando novamente no engajamento da díade e confirmando o sucesso da atividade. Em seguida, apresentou uma brincadeira que, segundo ela, havia sido 
planejada com antecedência, utilizando massinha de modelar. Porém, Pedro mostrou-se irritado, empurrando a massinha para longe e demonstrando náo gostar da textura pastosa. A resposta da mãe foi retirar a massinha da mesa e trocar por um quebra-cabeça, o que trouxe Pedro de volta à interaçấo. A iniciativa de troca de atividades foi um tema bastante discutido com a máe, em que ambas avaliaram esse comportamento como positivo. A mãe entendeu que precisaria trocar a atividade, mesmo que planejada, por uma que o filho estivesse mais habituado, como o quebra-cabeça. Foi concluído, nesse momento, que flexibilizar as estratégias maternas de acordo com a resposta do filho era importante, visando sempre ao foco na interação e ao desenvolvimento das habilidades sociocomunicativas.

No encontro seguinte, o pai relatou que o filho apontou para alimentos no supermercado enquanto passeavam, entendendo esse comportamento como atenção compartilhada. Foi esclarecido que a atenção compartilhada deveria ser compreendida a partir da noção de intencionalidade, ou seja: qual a intenção de Pedro com aquele comportamento? A literatura diferencia comportamentos de atenção compartilhada de acordo com as intençôes, como nos mostra Bosa (2002, p. 79):

Gestos indicativos possuem uma função protodeclarativa, isto é, servem para fazer comentários a respeito do mundo circundante a outras pessoas, enquanto os comportamentos de pedido, ao contrário, servem a um propósito protoimperativo: gestos para obter assistência.

Concluiu-se que aquele apontar utilizado por Pedro no supermercado não possuía função protodeclarativa, ou seja, o filho apontou para os alimentos na intençáo de que o pai os alcançasse para ele, para obter assistência. Justamente os comportamentos de compartilhamento que se encontram mais deficitários no autismo e, por isso, com foco na intervençáo, são os gestos protodeclarati- 
vos, em que a intenção é compartilhar interesses sociais por prazer (Mundy et al., 1996). Com isso, definiu-se que a interação durante as intervençóes deveria se centrar no desenvolvimento de gestos para compartilhamento de interesses comuns, para além daqueles simplesmente com função instrumental.

Esclarecidos esses aspectos teóricos, e sua repercussão na prática, prosseguiu-se para assistir aos vídeos. Nas cenas assistidas naquela sessão, a mãe observava quais gestos tinham função de protodeclarativa e quais tinham funçáo protoimperativa. Essa diferenciação mostrou como ela estava compreendendo aspectos mais sutis e específicos sobre os comportamentos interativos e sua importância para o desenvolvimento infantil, em especial, no contexto do autismo.

Entre as cenas observadas na autoscopia, a mãe questionou o quanto a criança compreendia a linguagem verbal que ela utilizava para se expressar: "Não sei se ele está entendendo, eu fico dizendo pra ele pegar a peça [do quebra-cabeça] e olhar pra mim, mas ele não faz isso".

É importante resgatar que o tema da dificuldade de compreensão verbal no autismo já havia sido discutido no terceiro encontro de autoscopia, resultando em orientaçóes sobre o uso de frases mais objetivas e curtas que facilitassem essa compreensão. Apesar de a orientação ser seguida, a criança ainda demonstrava dificuldades de compreensão dessas instruçóes verbais, o que sinalizou a necessidade da apresentação de mais "pistas" visuais. Considerando o fato de que alunos com autismo preferem e respondem melhor a estratégias de ensino por meio de pistas visuais do que verbais, a pesquisadora trouxe uma prática sedimentada pela literatura, considerada uma Prática Baseada em Evidências (PBE), que é a Comunicação Alternativa (Nunes e Nunes Sobrinho, 2010). ${ }^{4}$ A pesquisa-

4 Originadas nas áreas da Saúde e da Educação, as PBE consistem em uma abordagem que prevê um protocolo de passos de pesquisa para facilitar a comparaçáo dos diferentes achados, de modo a possibilitar a identificação entre seus resultados (Reichow et al., 2008). 
dora falou sobre o PECS-Adaptado, um sistema de Comunicação Alternativa que funciona por intercâmbio de figuras e é destinado especialmente a alunos com autismo que apresentam dificuldades de comunicação (Walter, 2000). A mãe e o pai demonstraram interesse na função de recursos visuais que servem como auxílio à compreensão da comunicação e combinaram de realizar buscas na internet sobre o assunto para conhecer melhor. Ao final, a mãe comentou: "Entendi. Se o Pedro náo entende direito o que eu falo, posso ser mais objetiva nas frases. Se mesmo assim ele ainda não compreender, posso usar figuras que mostram o que quero dizer."

No nono encontro, os pais estavam confiantes em seu desempenho, relatando perceber sucesso nas estratégias que a mãe tem utilizado. Na descrição das rotinas familiares, ela trouxe anotado em seu diário que o seguimento de "rotinas para dormir", combinado no segundo encontro, tem dado resultado. Após a leitura de um livro na cama, Pedro tem conseguido pegar no sono com mais facilidade, ficando menos sonolento durante o dia. Além desse aspecto, descreveu algumas preocupaçóes, como o tempo excessivo do filho em frente à televisão.

No momento da autoscopia, a mãe observou-se na interação com o filho e realizou uma autorreflexão sobre seu desempenho de forma negativa: "Olha só, eu não deveria ter interrompido nessa hora, quando ele estava atento e engajado na brincadeira". A pesquisadora, em contraponto, apresentou uma série de momentos em que a mãe interveio corretamente, adotando estratégias adequadas, que resultaram em um bom engajamento com o filho. Nesse confronto de percepçóes, pesquisadora e pais chegaram à conclusão de que os pais aprenderam bastante sobre desenvolvimento infantil e estratégias de intervenção nos encontros, a ponto de a mãe avaliar seu desempenho atual de forma mais crítica, percebendo aspectos que poderiam ser mais bem trabalhados.

No décimo encontro, os pais relataram que perceberam um desajeitamento motor em Pedro, que demonstra algumas dificul- 
dades nas brincadeiras, como pegar ou encaixar pequenas peças com a mão. Foi citado e explicado um auxílio que a mãe poderia fornecer ao filho, chamado tecnicamente de prompt, que se refere ao comportamento em auxiliar na execuçáo de uma atividade de forma verbal, física ou gestual (Kwee et al., 2009).

$\mathrm{Na}$ observação dos vídeos, verificou-se uma manutenção de estratégias efetivas para o engajamento da díade, especialmente utilizando atividades ou brinquedos do interesse de Pedro. Em alguns momentos, os vídeos exibiam a mãe ajudando Pedro em um encaixe de peças de um quebra-cabeça ou apontando para um objeto que ele procurava. Nessas ocasióes, ela praticava o que havia aprendido nas discussóes dos encontros: "Olha, eu alcancei pra ele a peça e ajudei a encaixar. Realizei um prompt físico, né?”, ou "Ele náo estava encontrando, aí apontei onde estava o brinquedo e ele achou. Esse foi um prompt gestual, não foi?”. A utilização dos termos técnicos mostrava à pesquisadora que os pais estavam entendendo como a teoria poderia ser aplicada à prática, norteando a intervençáo, além de evidenciar como a possibilidade de observar-se na intervenção favorecia uma análise sobre seu desempenho, auxiliando no incremento deste.

No décimo primeiro, e penúltimo encontro, os pais relataram sua percepção sobre uma melhor compreensão do filho a respeito das intençóes do outro. Nesse sentido, houve novamente uma conversa quanto ao construto da teoria da mente (Frith e Happé, 1994) - já abordado anteriormente no sexto encontro - e a importância de explicitar nossas intençôes na comunicação com uma pessoa com autismo.

Na observação dos vídeos, a mãe havia proposto uma atividade motora com o filho, em que foi construído um trajeto com barreiras que ambos percorriam, chamado de "circuito". Ela comentou que essa proposta foi resultante do que havia sido discutido no encontro anterior, quando relatou sua preocupaçáo com os aspectos motores do filho: "achei que seria legal fazer uma atividade que 
exigisse habilidade motora do Pedro". A proposta foi avaliada por todos como produtiva, porém diminuía a interação face a face, como o contato visual, já que ambos estavam em movimento e mais distantes um do outro.

Em um segundo momento, foi exibida uma cena em que ambos brincavam com tinta e massa de modelar. A máe percebeu o filho muito direcionado para os brinquedos, com pouco compartilhamento sobre eles com ela: "Ele está só com a massinha, sem brincar comigo. O que fiz foi trazer a massinha para perto do meu rosto. Aí ele se interessou e conseguimos rir e trocar olhares novamente". É importante ressaltar que essa estratégia já havia sido utilizada com sucesso no quinto encontro e, desde entáo, passou a fazer parte do repertório materno para engajar-se com o filho. A pesquisadora destacou a utilizaçáo dessa estratégia novamente, ao que a mãe se mostrou satisfeita com seu desempenho evidenciado nos vídeos.

No último encontro, os pais iniciaram os relatos das rotinas familiares descrevendo a importância e o fato de o filho ter mais autonomia na hora da alimentaçáo, quando precisa de ajuda com frequência. A pesquisadora enfatizou que a aprendizagem de comportamentos específicos, como a alimentaçáo, pode ocorrer por meio da ajuda dos pais, para que Pedro leve corretamente a colher até a boca (prompt físico), ou também pode ocorrer por observação do outro realizando esses comportamentos. Nesse sentido, foi abordado o conceito de aprendizagem vicária (Bandura, 1997) e como a máe poderia ensinar esses comportamentos atuando como modelo para o filho.

Os vídeos foram realizados durante a hora da alimentação. Ao observá-los, o pai comentou: "Olha o que a gente falou agora: a mãe poderia ter comido junto, mostrando pra ele como se come, não é?". A mãe concordou e complementou: "Sim, aí seria o caso da aprendizagem vicária! É mais uma estratégia bem interessante que podemos usar". 
Esse dia foi marcado por relatos de satisfação com o resultado dos demais encontros e com a sensaçáo de estarem conseguindo desenvolver uma interaçáo com o filho, quando comparada ao início da intervenção.

A gente não sabe direito como fazer, o que fazer para interagir. Mas olhando nos vídeos é diferente, a gente se vê fazendo e percebe outras possibilidades. Coisas que podia fazer melhor ou ainda outras formas de atingir aquele objetivo com o Pedro. Acho que aprendemos muito!

A pesquisadora concordou com a percepçáo de uma melhora na qualidade das interaçóes desde o início e de como os pais se encontravam hoje mais seguros e hábeis para desenvolver as competências do filho. Com isso, encerraram-se os encontros previstos para a realização da pesquisa e para a formação dos pais.

\section{Consideraçóes finais}

O objetivo deste capítulo foi descrever o processo de autoscopia sendo utilizado no contexto da formaçáo de pais, para eles atuarem como agentes de intervenção diretamente no desenvolvimento de habilidades sociocomunicativas do filho. Por meio de inspeção visual, foi possível observar uma tendência crescente na frequência de comportamentos sociocomunicativos da mãe e da criança com autismo, após o início dos encontros de autoscopia. Esse resultado demonstra que os encontros de formação com os pais têm uma relação causal e estatisticamente significativa com o aumento daqueles comportamentos.

A descrição dos encontros mostra que os pais relataram rotinas familiares para, em seguida, assistirem aos vídeos com a pesquisadora e refletirem sobre a intervenção. Chama a atenção, nos primeiros encontros, a presença marcante de um sentimento de insegurança materno sobre como proceder na intervenção com o 
filho. À medida que os vídeos iniciais são observados e as orientaçôes sobre como o ambiente poderia ser otimizado são fornecidas, somados à compreensáo de especificidades do autismo por meio da discussão de textos, observa-se uma gradual diminuição desse sentimento. No quarto e quinto encontros, a mãe já verbalizava sua satisfação ao avaliar positivamente seu desempenho nos vídeos. Além do comportamento materno, foram discutidos, nos encontros, também alguns comportamentos da criança com autismo, como a agressividade e o transtorno de sono. As estratégias foram sugeridas pela pesquisadora e desenvolvidas pela mãe, resultando na amenizaçáo desses comportamentos, o que contribuiu para que ambos conseguissem se engajar mais nas interaçôes.

Um dos aspectos importantes foi a escolha de textos técnicos a respeito dos temas tratados nos encontros. Alguns deles foram escolhidos antes mesmo de ter início a autoscopia, na observaçáo dos vídeos da linha de base, quando se percebeu a importância de os pais conhecerem melhor as características do autismo e as abordagens para intervençáo. As discussóes sobre os textos indicaram resultados interessantes, como o descrito no quarto encontro, quando exemplos de comportamentos agressivos descritos no texto foram comparados com o de Pedro, fazendo com que os pais associassem o conhecimento teórico a uma aplicação prática. O mesmo ocorreu no sexto encontro, quando, após leitura sobre o brincar e o desenvolvimento de habilidades sociocomunicativas, a mãe passou a utilizar termos técnicos para descrever alguns comportamentos observados na autoscopia.

Shulman (1986), autor que se dedicou a estudar a formação de professores, explica que as práticas de ensino são influenciadas tanto pelo conteúdo do conhecimento quanto pela forma como esse conhecimento é estruturado. Para isso, é essencial a articulação entre duas formas de conhecimento, propostas pelo autor: o conhecimento pedagógico, de conteúdo, e o conhecimento do contexto educacional. Enquanto o primeiro diz respeito à capacidade de 
transformar o conhecimento técnico em formas pedagogicamente acessíveis, o segundo se refere ao conhecimento do contexto educacional. Nessa perspectiva é que Shulman (1986) propóe que o saber propositivo (conteúdo) seja complementado pelo conhecimento de caso (contexto). No que se refere à formação dos pais, estes já possuíam ou conheciam o caso, ou seja, os gostos, preferências e comportamentos de seu filho, faltando agregar o conhecimento de conteúdo. A escolha e a discussão dos textos sobre autismo e estratégias para engajamento possibilitaram que os pais associassem as duas formas de conhecimento na prática interventiva, por meio dos encontros de autoscopia.

\section{Referências}

ABREU, A. e THEODORO, M. "Família e autismo: uma revisão da literatura”. Contextos Clínicos, v. 5, n. 2, pp. 133-42, 2012.

AMSBARY, J. e AFIRM Team. "Parent implemented intervention". National Professional Development Center on Autism Spectrum Disorders. Chapel Hill, NC: FPG Child Development Center, University of North Carolina, out. 2010. Disponível em: http://afirm.fpg.unc.edu/parent-implemented-intervention. Acesso em: 16 jan. 2020.

BANDURA, A. Self-efficacy: the exercise of control. Nova York: W. H. Freeman, 1997.

BERNERT, D. "A importância do brincar no desenvolvimento da criança com o TEA". In OMAIRI, C. et al. (orgs.). Autismo: perspectivas no dia a dia. Curitiba: Ithala, 2013, pp.165-73.

BOSA, C. "Atenção compartilhada e identificação precoce no autismo". Psicologia: Reflexão e Crítica, v. 15, n. 1, pp. 77-88, 2002.

e SOUSA, A. "Interação mãe-criança e desenvolvimento atípico: a contribuição da observação sistemática”. In PICCININI, C. A. e MOURA, M. L. S. (orgs.). Observando as primeiras interaçōes pais-bebê-criança. São Paulo: Casa do Psicólogo, 2007, pp. 237-58.

BOWEN, M. "Alcoholism as viewed through family systems theory and family psychotherapy". Annals of the New York Academy of Sciences, v. 233, n. 1, pp. 115-22, 1974.

BRASIL. Diretrizes de atenção à reabilitação da pessoa com Transtornos do Espectro do Autismo (TEA). Brasília: Ministério da Saúde, 2014. 
CHARLOP, M. H. et al. "The power of parents: parent-implemented interventions for young children with autism". In et al. (orgs.). Keeping it Real: Naturalistic Teaching Strategies (NaTS) for play and social skills with children with Autism Spectrum Disorder. Springer: Cham, 2018, pp. 53-70.

CIDAV, Z. et al. "Implications of childhood autism for parental employment and earnings". Pediatrics, v. 129, n. 4, pp. 617-23, 2012.

DEAK, G. O. e TRIESCH, J. "Origins of shared attention in human infants". In FUJITA, K. e ITAKURA, S. (orgs.). Diversity of cognition. Kioto: Kioto University Press, 2006, pp. 331-63.

FÁVERO, M. A. B. e SANTOS, M. A. dos. "Autismo infantil e estresse familiar: uma revisão sistemática da literatura". Psicologia: Reflexão e Crítica, v. 18, n. 3, pp. 358-69, 2005.

FERNANDES, F. D. "Famílias com crianças autistas na literatura internacional". Jornal da Sociedade Brasileira de Fonoaudiologia, v. 14, n. 3, pp. 427-32, 2009.

FRITH, U. e HAPPÉ, F. "Autism: beyond theory of mind". Cognition, v. 50, n. 1, pp. 115-32, 1994.

KASHINATH, S. et al. "Enhancing generalized teaching strategy use in daily routines by parents of children with autism". Journal of Speech, Language and Hearing Research, v. 49, n. 3, pp. 466-85, 2006.

KWEE, C. S. et al. "Autismo: uma avaliação transdisciplinar baseada no programa TEACCH”. Revista CEFAC, v. 11, n. 2, pp. 217-26, 2009.

MAXWELL-HORN, A. e MALOW, B. A. "Sleep in autism”. Seminars in Neurology, v. 37, pp. 413-8, 2017.

MAYES, S. D. e CALHOUN, S. L. "Ability profiles in children with autism: influence of age and IQ". Autism, v. 7, n. 1, pp. 65-80, 2003.

MORATO, E. M. Linguagem e cognição: as reflexöes de LS Vygotsky sobre a ação reguladora da linguagem. São Paulo: Plexus, 1996.

MUNDY, P. et al. "Defining the social deficits of autism: the contribution of nonverbal communication measures". Journal of Child Psychology and Psychiatry, v. 27, pp. 657-69, 1986.

NATIONAL PROFESSIONAL DEVELOPMENT CENTER ON AUTISM SPECTRUM DISORDERS - NPDC. Evidence-Based Practices, 2019. Disponível em: http://autismpdc.fpg.unc.edu. Acesso em: 16 jan. 2020.

NATIONAL RESEARCH COUNCIL - NRC. Educating children with autism. Washington, DC: National Academy Press, 2001. Disponível em: http:// www.nap.edu/openbook.php. Acesso em: 16 jan. 2020.

NORTON, P. e DREW, C. "Autism and potential family stressors". The American Journal of Family Therapy, v. 22, n. 1, pp. 67-76, 1994. 
NUNES, D. R. P. e NUNES SOBRINHO, F. P. “Comunicação alternativa e ampliada para educandos com autismo: consideraçóes metodológicas". Revista Brasileira de Educação Especial, v. 16, n. 2, pp. 297-312, 2010.

NUNES, L. R. O. P. e WALTER, C. C. F. "Pesquisa experimental em educação especial". In ___ (org.). Novas trilhas no modo de fazer pesquisa em educação especial. São Carlos: Marquezine \& Manzini: ABPEE, 2014, pp. 27-52.

OLIVEIRA, J. J. M. Intervenção centrada na familia: influência nas habilidades comunicativas e interativas da criança com Transtorno de Espectro Autista e no empoderamento parental (dissertação). Universidade Federal de Santa Maria, 2016.

PARKER, R. I. et al. "Combining nonoverlap and trend for single-case research: Tau-U”. Behavior Therapy, v. 42, n. 2, pp. 284-99, 2011.

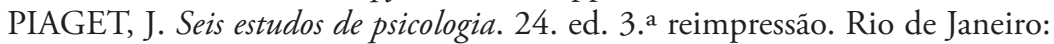
Editora Forense Universitária Ltda, 2003.

REICHOW, B. et al. "Development of the evaluative method for evaluating and determining evidence-based practices in autism". Journal of autism and developmental disorders, v. 38, n. 7, pp. 1311-9, 2008.

SAMPIERI, R. H. et al. Metodologia de pesquisa. 5. ed. Porto Alegre: Penso, 2013.

SCHMIDT, C. et al. "Autoscopy as a methodological resource in the interventions with autism: empirical aspects". Revista Psicologia: Teoria e Prática, v. 21, n. 3, pp. 418-36, 2019.

SHULMAN, L. S. "Those who understand: knowledge growth in teaching". Educational Researcher, v. 15, n. 2, pp. 4-14, 1986.

SILVA, A. M. e CIA, F. Problemas de comportamento: conceituação e possibilidade de intervenção para pais e professores. Jundiaí: Paco Editorial, 2012.

SILVA, N. M. V. et al. "Do vídeo para o texto escrito: implicaçôes para a análise da interação”. Psicologia em Revista, v. 20, n. 3, pp. 513-28, 2014.

SOUDERS, M. C. et al. "Sleep in children with autism spectrum disorder". Current Psychiatry Reports, v. 19, n. 6, p. 34, 2017.

STAHMER, A. C. e PELLECCHIA, M. "Moving towards a more ecologically valid model of parent-implemented interventions in autism". Autism, v. 19, n. 3, pp. 259-61, 2015.

STAINBACK, S. e STAINBACK, W. Inclusão: um guia para educadores. Porto Alegre: Artmed, 1999.

WALTER, C. Efeitos da adaptação do PECS associada ao curriculum funcional natural em pessoas com autismo infantil (dissertação). Universidade Federal de São Carlos, 2000.

WETHERBY, A. M. et al. "Parent-implemented social intervention for toddlers with autism: an RCT". Pediatrics, v. 134, n. 6, pp. 1084-93, 2014. 
256 Autoscopia: uma ação reflexiva sobre a prática docente

WONG, C. et al. "Evidence-based practices for children, youth, and young adults with autism spectrum disorder: a comprehensive review". Journal of Autism and Developmental Disorders, v. 45, n. 7, pp. 1951-66, 2015.

YANG, Z. et al. "Circadian-relevant genes are highly polymorphic in autism spectrum disorder patients". Brain and Development, v. 38, n. 1, pp. 91-9, 2016.

ZAIDMAN-ZAIT, A. et al. "Examination of bidirectional relationships between parent stress and two types of problem behavior in children with autism spectrum disorder". Journal of Autism and Developmental Disorders, v. 44, n. 8, pp. 1908-17, 2014. 